\title{
Applications of Nanotechnology in Agricultural Waste-Review Paper
}

Thiruvangium Henry Sukirtha ${ }^{1 *}, \mathrm{~N}$ Saranya ${ }^{2}$

\author{
${ }^{1}$ Associate Professor, Department of Microbiology, Nehru arts and Science College, Coimbatore \\ ${ }^{2}$ Assistant Professor, Department of Biotechnology, Nehru arts and Science College, Coimbatore
}

DOI: $10.36347 /$ sajb.2020.v08i09.001

| Received: 31.08 .2020 | Accepted: 08.09.2020 | Published: 12.09.2020

*Corresponding author: Thiruvangium Henry Sukirtha

Abstract

The forecast that in 2050 our planet will be populated by more than 9 billion individuals is very dependable. This will present significant issues with nourishment, water and vitality supply, especially in less-created nations. Taking into account that the human weight over normal assets has just arrived at basic levels, global organizations, for example, the World Bank and UN. Food and Agriculture Organization (FAO) are requesting logical research so as to distinguish imaginative answers for help the essential division. Nanotechnology is perceived by the European Commission as one of its six "Key Empowering Technologies" that add to economical seriousness and development in a few mechanical segments. The present difficulties of manageability, nourishment security and environmental change are connecting with specialists in investigating the field of nanotechnology as new wellspring of key enhancements for the rural division. In any case, solid commitments are as yet unsure. In spite of the various potential points of interest of nanotechnology and the developing patterns in productions what's more, licenses, agrarian applications have not yet made it to the market. A few components could clarify the shortage of business applications. From one viewpoint, industry specialists stress that rural nanotechnology doesn't exhibit an adequate financial come back to offset the high beginning creation ventures. Then again, new nanotech guideline in the EU may make administrative vulnerability for items as of now available and influence open discernment. In any case, late investigations exhibit that general supposition isn't negative towards nanotechnology and that the presentation available of nanotech items with clear advantages will probably drive purchaser acknowledgment of progressively delicate applications. The quick advancement of nanotechnology in other key businesses may after some time be moved to agrarian applications also, and encourage their improvement.

Keywords: Nanotechnology, Agriculture, Innovation, Venture, Vulnerability.

Copyright @ 2020: This is an open-access article distributed under the terms of the Creative Commons Attribution license which permits unrestricted use, distribution, and reproduction in any medium for non-commercial use (NonCommercial, or CC-BY-NC) provided the original author and source are credited

\section{Environmental importance of the use of agricultural waste}

Fundamentally is imperative to make mindfulness on the huge amounts of horticultural/food squander that is lost each year, moment and second around the globe. It gauges that every year, around 33\% food created for human utilization on the planet is lost or squandered. The worldwide volume of food wastage is evaluated to be 1.6 Gtonnes of "essential item reciprocals", while the complete wastage for the palatable some portion of food is 1.3 Gtonnes. This sum can be weighed against complete farming creation (for nourishment and non-nourishment utilizes), which is around 6 Gtonnes. Without representing GHG emanations from land use change, the carbon impression of food created and not eaten is evaluated to 3.3 Gtonnes of $\mathrm{CO} 2$ comparable: accordingly, nourishment wastage positions as the third top producer after USA and China. Universally, the blue water impression (for example the utilization of surface and groundwater assets) of food wastage is about $250 \mathrm{~km}$, which is equal to the yearly water release of the Volga stream, or multiple times the volume of Lake Geneva. With such circumstances, it appears to be certain that a decrease of food wastage at worldwide, local, and national scales would have a generous constructive outcome on regular and cultural assets. Food wastage decrease would not just maintain a strategic distance from pressure on rare characteristic assets yet in addition decline the need to raise food creation by 60 percent to fulfill the 2050 populace need [17]. Luckily, various types of techniques have been proposed for reuse rural waste rather than stay in the earth. These deposits happened by handling, creation and gather of grain items, organic products, vegetables and trees, and through stock cultivating. They are delivered in enormous sums worldwide and either consumed in the field or utilized as animal feed [56]. Horticultural buildups are lignocellulosic materials [8]. Therefore, these squanders are utilized on creation of modern items, for example, natural acids, biofuels, protein improved 
feed, smell compounds, bioactive optional metabolites, microbial shades, mushroom and enzymes as substrate [50].

\section{New opportunities}

There are at least two fundamental aspects in the management of primary production on which research can produce significant advances to meet future needs: (i) increased production rate and crop yield, (ii) increased efficiency of resource utilization and (iii) reduction of waste production.

\section{Increase production rate and crop yield}

Crop yield increases have been achieved by utilizing plant breeding, fertilizers and plantprotection-products [60]. Since Green Revolution, which occurred during the decade 1960- 1970, agricultural productivity growth has been in decline and at present we need a second revolution in agricultural technology [16]. However, rather than an increase in the doses of traditional agronomic factors, it is realistic that significant improvements in crop yield will come from improving the efficiency of the photosynthetic process.

Food security is based on plant photosynthesis. About $85 \%$ of plant species are C3 plants which are the most common and efficient in photosynthesis in cool wet climates. They include the cereal grains: wheat, rice, barley, oats, cotton, sugar beets, tobacco and soybean. In addition, most trees and most lawn grasses such as rye and fescue are $\mathrm{C} 3$ plants. Photosynthetic organisms are able to convert radiant energy from solar light into chemical energy which is stored in sugars. The process coupled biophysical processes-absorption of photosynthetically active radiation (PAR) and electron transport - and biochemical processes - NADPH and ATP. Some targets have been identified to improve the photosynthesis [26].

Among these, the most serious candidate is the photosynthetic enzyme ribulose-1,5-bisphosphate carboxylase/oxygenase-in short, Rubisco. This molecule catalyzes the addition of $\mathrm{CO} 2$ to the five-carbon compound ribulose bisphosphate, in the initial phase of the Calvin-Benson cycle [52]. Rubisco also reacts with oxygen in photorespiration. This is considered a wasteful process; in fact, it was verified that in $\mathrm{C} 3$ plants (25C, current atmospheric [CO2]), about $30 \%$ of fixed $\mathrm{C}$ is lost to recover Rubisco. For that reason, Rubisco is considered the physiological "bottleneck" of photosynthesis [31].

Let us take a step back and reconsider the biophysical processes of photosynthesis. More precisely, we take into consideration the energy source that promotes the process, that is, solar radiation. Visible light corresponds to $43 \%$ of solar light; it lies between 400 and $700 \mathrm{~nm}$ in the solar spectrum and approximately coincides with PAR. When sunlight reaches the leaf surface the photosynthetic pigments chlorophyll-a and chlorophyll-b absorb photons as allowed by their absorption spectrum and provide the energy to the biochemical pathway of photosynthesis [55].

The process is highly inefficient, the solar energy conversion efficiency (ratio of the energy stored to the energy of light absorbed) being 2.4 and $3.7 \%$, respectively, for $\mathrm{C} 3$ and $\mathrm{C} 4$ healthy crops [61].

\section{Plant nanobionics and photosynthesis}

For years, important discussions and studies are under way to fill the knowledge gaps in order to overcome the limitation of photosynthesis. Significant efforts are made working on different strategies, including (i) engineering $\mathrm{C} 3$ crops to use $\mathrm{C} 4$ photosynthesis pathway [22], (ii) improving the efficiency of Rubisco [3], (iii) modifying the chlorophyll antenna size of chloroplast photosystems [32], (iv) improving the recovery rate from photoinhibition [58] and broadening the photosynthetic light waveband [28]. According to Evans, "recent technological developments now provide us with the means to engineer changes to photosynthesis that would not have been possible previously" [14].

There is no doubt whatsoever that nanotechnology is among these new tools. The scientific literature devoted to the relationships between plants and nanomaterials is not very large yet. However, a relatively large body of papers reported the positive effects of nanomaterials on photosynthesis. Early studies considered titanium oxide nanoparticles (nTiO2). And that is because the high photocatalytic activity of anatase crystal nTiO2 was hypothesized to have a role in the improvement of light absorbance by plant leaves, thus sustaining an increase in photosynthesis. In particular, it was demonstrated that nTiO2 protects the chloroplast from aging due to photochemical stress [23,24,19], activates Rubisco carboxylation promoting an enhancement of the photosynthetic rate $[19,20,28]$ and positively influences biophysics traits of photosynthesis, such as electron chain transport and Chl-photophosphorylation activity. Finally, in addition to photosynthesis, nTiO2 improves leaf water conductance and transpiration rate [46].

More recently, the original idea to merge nanomaterials with living plants to enhance their native functions and to give them non-native functions has been more accurately focused. This approach assumed the name of "plant nanobionics" [25] and potentially allowed to engineer faster-growing plants and become the key factor to design and develop artificial photosynthetic systems, a potential source of clean energy [21, 40]. In addition, it could also lead to other innovations that we cannot imagine at this time. 
The first report demonstrating an application of plant nanobionics was provided by a research group from MIT. A suspension of single-walled carbon nanotubes (SWCNTs) was supplied by perfusion to leaves of Arabidopsis thaliana and to isolated chloroplasts of Spinacia oleracea. In both cases the SWCNTs were observed within the thylakoids and no symptoms of stress were recorded. The treatment increased the electron transport rate compared to control and the shelf life of isolated chloroplasts was extended by about $2 \mathrm{~h}$. The authors proposed that the semiconductor SWCNTs have a high electrical conductance and are able to capture solar energy in wavelengths that are weakly absorbed by chloroplasts. In particular, an enhancement in the light absorption profile of chloroplasts by increasing the light energy capture in UV and N-IR ranges of the spectrum was supposed [25]. In their experimental conditions the authors observed that SWCNT-chloroplast assemblies promoted over three times a higher photosynthetic activity than control and enhanced electron transport rate. On the one hand, there is no doubt that still extensive research would be needed to see the effects of plant nanobionics in terms of increased production of sugars as well as crop yield. On the other hand, the enhancement of a basic plant function in response to incorporation of nanomaterials was demonstrated as proof of concept [25].

\section{Increase in efficiency of resource utilization Principles of plant nutrition and fertilization}

Optimal crop nutrition is a fundamental requirement for food security, which means that fertilization has a prominent role in modern agriculture. Crop yield is highly dependent on macronutrients $(\mathrm{N}, \mathrm{P}$, $\mathrm{K}, \mathrm{S}, \mathrm{Ca}, \mathrm{Mg}$ ) and micronutrients $(\mathrm{B}, \mathrm{Fe}, \mathrm{Mn}, \mathrm{Cu}, \mathrm{Zn}$, $\mathrm{Mo}$, and $\mathrm{Cl}$ ) input to agricultural lands [51]. A conservative estimate obtained by examining the results of a number of long-term field studies on crop production suggested that from 30 to $50 \%$ of crop yield is attributable to commercial fertilizer nutrient inputs [30].

Nutrient use efficiency (NUE) is a measure of how well plants use the available mineral nutrients. In all agroecosystems NUE of crop plants is lower than 50\% due to physical and chemical soil properties, leaching, gaseous losses and fertilizer characteristics [28], this is, for instance, in the case of urea [CO(NH2)2] which is one of the most important $\mathrm{N}$-fertilizers $(46 \% \mathrm{~N}$ by weight). Plants are not able to take up this molecule but the byproducts produced in soil after urea decomposition due to hydrolysis, volatilization and urease soil enzyme [8]. If ammonia is not readily assimilated by plant roots, then, large amounts of nitrogen are lost.

Since the fertilizer use between 1950 and 2000 increased about 20-fold and 7-fold for $\mathrm{N}$ and $\mathrm{P}$, respectively [13], we have a 2 -fold consequence. On one side, the lower efficiency of fertilizer dose implies that to maintain high production the production costs are increasing. From one another we have risks of environmental pollution.

As for micronutrients, though they are present in plants in concentrations generally below 100 ppm, they play fundamental physiological roles in plant metabolism, being activators of specific enzymes. Many micronutrients stimulate or are part of plant defensive systems against diseases or abiotic stress [7]. Moreover, plants are the sources of these essential elements for animals and humans [59]. Soil micronutrient deficiencies or insufficient micronutrient availability in soils limit crop productivity and nutritional value of food. The most common method of micronutrient application for crops is soil application. Under unfavorable conditions (neutral to alkaline soil $\mathrm{pH}$ ) microelements frequently precipitate and become less bioavailable [2]. It has been reported that the fertilizer-micronutrient use efficiency by crops is lower than 5\% [36]. To overcome the soil limiting factors, a second strategy widely used to provide micronutrients to crops is via leaf treatments. However, plants primarily absorb nutrients through their roots. The amount of micronutrients that can be absorbed by leaves is limited, and they are not transported to the roots via the phloem (basipetal flux) [34].

\section{Smart fertilizers for crop nutrition}

Best management practices for fertilization are those that support the achievement of the main objectives of sustainable agriculture: productivity, profitability and environmental health. The improvement of NUE in crop production is one of the main pillars of this vision [62, 29, 47]. Nanotechnology can play an important role in the strengthening of agriculture sustainability, having provided the feasibility of the so-called "smart fertilizer." In other words, nanostructures act as carriers of nutrients and allowed their controlled release.

The design of smart fertilizers strongly influences the nutrient release and the minimization of losses. In field conditions such products are provided to crops via irrigation or sprayed to plant canopies. Through the application of nanotechnologies in agriculture the fertilization will be carried out in different ways. In particular, the nutrient elements will be possibly administered as follows:

i. Delivered as particles or emulsions of nanoscale dimensions: a research body is being developed which aims to clarify whether nanoparticles (e.g., fullerenes, carbon nanotubes, $\mathrm{nTiO} 2$, and $\mathrm{nSiO} 2$ ) in different growth stages of crops may or may not partially replace traditional fertilizer practices $[35,33]$.

ii. Encapsulated inside nanostructures designed to allow the controlled release of nutrients (Figure $1)$ : to do so the outer shell of nanocapsules is 
engineered and programmed to open when stimulated by environmental factors or man-induced pulses. Here are some examples of possible control mechanisms [44]:

- Slow release: The capsule releases its payload slowly over a longer period of time so as to synchronize plant assimilation and limit leaching.

- Quick-release: The capsule shell breaks upon contact with a leaf surface.

- Specific release: The nutrient release occurs through a recognition mechanism between a receptor (molecule or functional group) bound to the shell and a target molecule.

- Moisture release: The shell breaks down and releases nutrients in the presence of water

- $\quad$ H release: The shell breaks up only in specific alkaline/acidic environment (e.g., within plant tissues or inside a cell).

- Magnetic/ultrasonic pulses: The shell opens in response to a magnetic or ultrasonic pulse emitted by a man-controlled system (precision agriculture).

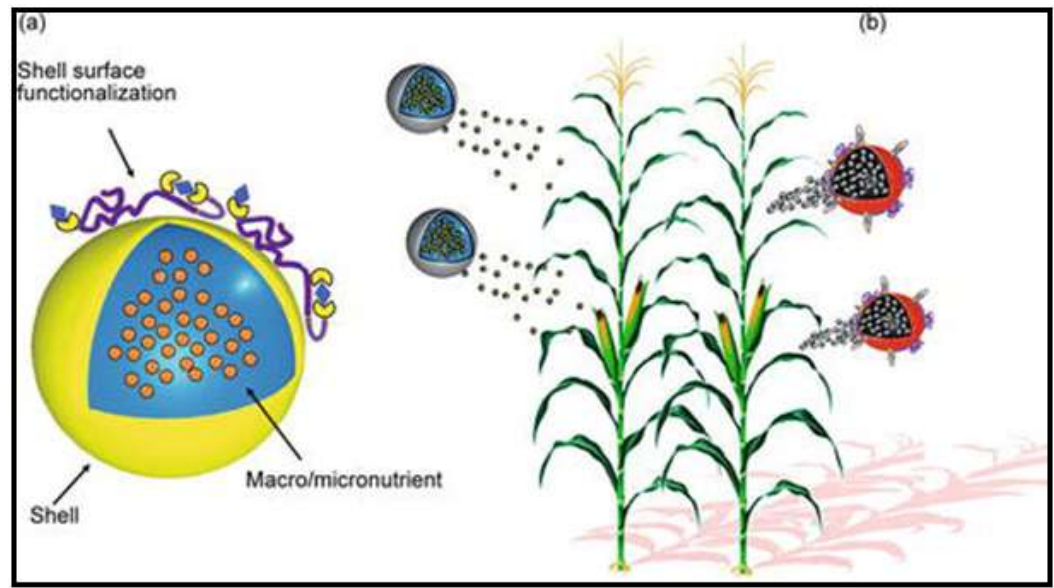

Fig-1: (a) Model of nanocapsule containing marco/microelements. Examples of opening strategies of nanocapsule: (b) release of nutrients as function of time to avoid or limit nutrient losses or designed to occur when a molecular receptor binds to a specific chemical

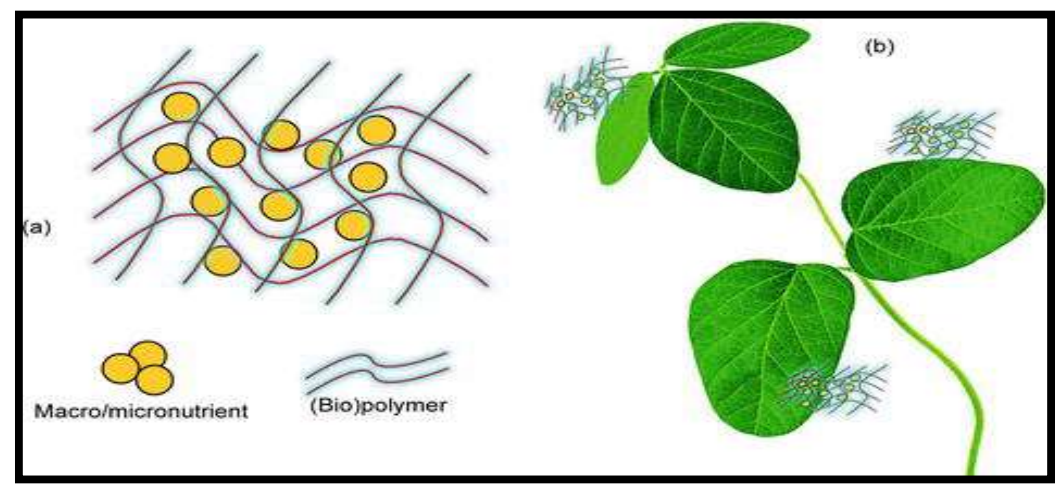

Fig-2: (a) Model of biopolymeric structure containing marco/microelements. (b) Deposition onto the crop leaf after spray treatment

iii. Delivered in a complex formed by nanocapsules incorporated in a matrix of organic polymers of biological or chemical origin which act as a carrier (Figure 2): Both of them provide the expected traits to nanofertilizers. However, natural substances should be preferred as they are easy available, biodegradable and cheaper than the synthetic ones [4]. The properties of the new nanostructure allow a controlled release of nutrients as a function of time or after interactions with the environment. Studies are currently being conducted to test the potential of different materials, such as zeolites $[10,11,12]$, polyacrylic acid [49] and chitosan [57].
As far as the effectiveness of nanofertilizers is concerned, it must be said that the potential of nanofertilizer application has not been extensively studied yet. However, some successful examples demonstrated that such new formulates significantly improve the efficiency of fertilization $[48,39,15,18,37$, $45,38,1]$.

The challenge for research is to develop and test carriers that allow the controlled release of nitrogen, following a schedule possibly synchronized with the physiological needs of crops. We are still at a stage where studies on interactions between nanomaterials and biota provide conflicting results. This occurs also for studies on nanofertilizers. 


\section{Large-scale use of nanofertilizers}

There is no question that nanotechnology is a revolutionary science. However, in several fields of application there are good and bad components to deal with. Referring to nanofertilizers it should be emphasized there are still some uncertainties.

Despite great expectations, both large-scale industrial production of nanofertilizers and their utilization are yet to be realized. This is certainly due to the lack of clear legislative indications. For example, in the European Union, the work to prepare a legislative and regulatory framework is actively under way.

Another controversial point is that, when we look at the recent literature, surprisingly, it can be easily verified that research has neglected macronutrients to focus more in the direction of micronutrients [41, 5, 43]. This is noteworthy; in fact, although microelements are very important in plant metabolism, crop yield is mainly influenced by $\mathrm{N}, \mathrm{P}$ and $\mathrm{K}$ nutrition.

In conclusion, there are still great expectations that need to be satisfied. In accordance with international and national agencies dealing with sustainable agricultural development and food security (FAO, UNEAP, USEPA, EEA), applied research on nanotechnology in agriculture should be re-oriented according to precise priorities. The development of $\mathrm{N}$ and $\mathrm{P}$ nanofertilizers is certainly one of such priorities.

\section{Nanobiosensors}

Nanobiosensors (NBSs) are analytical devices having at least one dimension no greater than $100 \mathrm{~nm}$. Structured as nanoparticles, nanotubes, nanowires or nanocrystals, NBSs are manufactured for monitoring plant fractions, soil and water in the agroecosystem. By exploiting the physico-chemical properties of nanomaterials, NBSs represent a powerful tool with advanced and improved features compared to existing analytical sensors and biosensors that combine biological element recognition with chemical or physical principles. Biological information is converted by a transducer into a signal yielded by an electronic component. This capability allows the agronomist with an accurate and real-time control of the needs of crops in terms of water and nutrient supply and early symptoms of diseases.
A properly designed network of nanosensors would allow the optimization of crop yield and the most efficient agronomic management of factors, such as fertilizers, water, herbicides and pesticides. Typically, an NBS consists of three components: i. Biological sensitive probe: a sensing element which interacts with the target (biomolecule) producing a signal proportional to the biomolecule concentration. Some examples of probe/ biomolecule interaction are: (i) antibody-antigen, (ii) nucleic acid interactions (iii) enzymatic interactions and (iv) cellular interactions (i.e., microorganisms, proteins). ii. Transducer: a physical component responsible for converting the recognition signal events into a digital signal. The nanomaterial properties suggest managing different kinds of signals such as electrochemical, optical and mass-sensitive signals. iii. Data recording unit: it consists of an amplifier and signal processor that are responsible for data transferred and storage. For plant monitoring applications, we therefore deploy a monitoring system comprising a hierarchical arrangement of nano- and microscale network devices (Figure 3). The control units manage clusters of nanodevices and the data flow. Data should be directed to gateways which relay the collected data from the nanonetwork to the Internet. Large numbers of nanoscale-sensing devices could be positioned on the plant leaves through suspension in a spray treatment. At this time, this technology is at its very early stage. For its refinement, it will also be necessary to design spraying machines capable of adequately distributing suspensions with nanosensors onto crop canopies. Nanonetworks for monitoring plant conditions can alert automatically suggesting a more efficient usage of crop inputs (e.g., fertilizers, water, pesticide, etc). Thus, the real time and monitoring of the crop growth lead to accurate and on-time decisions, reduced costs and waste, improved quality of production and above all sustainable agriculture Figure 3.

Finally, the use of nanobiosensors for high-resolution crop monitoring could be a very useful tool for plant science research. The real-time continuous measurement of plant metabolites and hormones will make a deeper understanding and control of plant biosynthetic pathways in ways not possible. 


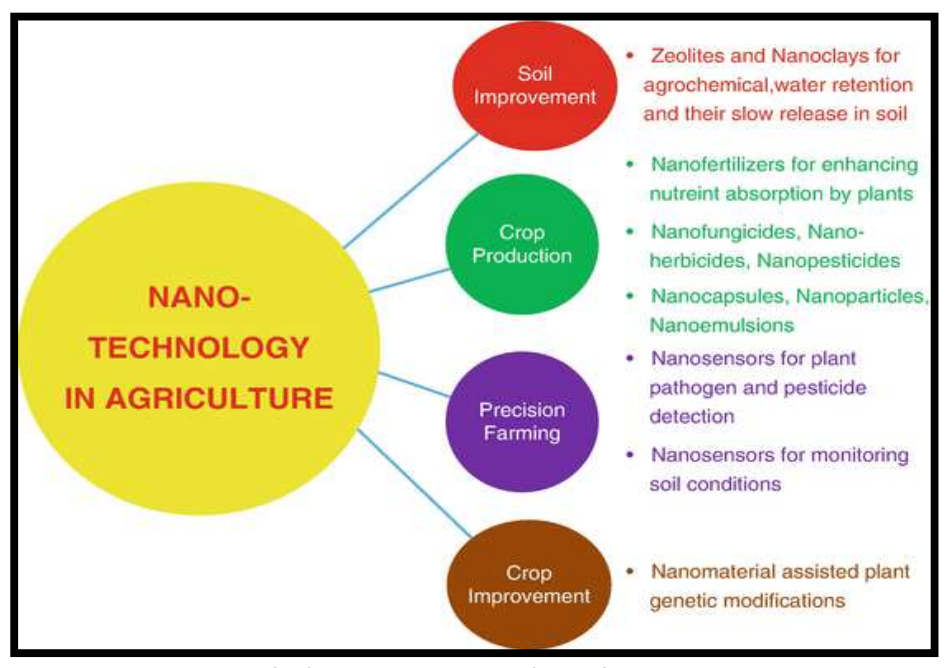

Fig-3: Nanotechnology in agriculture

\section{Agricultural residues for production of nanomaterials}

There is a growing awareness of the importance of sustainability, in particular bearing in mind the increase of global population. This issue is intimately linked to the implementation of a circular economy based on regeneration of resources. One of the pillars of circular economy is waste reduction. Organization for Economic Cooperation and Development (OECD) defines agricultural waste as "waste produced as a result of various agricultural operations including manure and other wastes from farms, poultry houses and slaughterhouses; harvest waste; fertilizer run-off from fields; pesticides that enter into water, air or soils; and salt and silt drained from fields". A meaningful proportion of agri-food production is lost in the form of residues and wastes. For this reason, it will be of the utmost importance to explore innovative technologies capable of providing new opportunities to achieve full sustainability. It is believed that nanotechnology can significantly contribute also in this direction. The development of advanced methods for valorization and the exploitation of agricultural raw materials and wastes are relevant contributions of nanotechnology toward strengthening the basic principles of the circular economy. The following are suggested as illustrative examples of this concept.

\section{Cellulose nanofibers}

Cellulose is the most abundant biopolymer available on the Earth, being the main component of plant tissues. The primary occurrence of cellulose is the existing lignocellulosic material in wood which is the most important industrial source of cellulose. Other cellulose-containing materials include agriculture residues, water plants, grasses and other plant substances. It is estimated that $1011-1012$ tons per year of cellulose are worldwide produced by photosynthesis. In plant tissues micro and macrofibrils represent the construction units of the hierarchical structure of cellulose fibers Figure 4. Microfibrils, in turn, consist of elementary fibrils (nanofibres) which have a diameter comprised in the range 3-35 $\mathrm{nm}$ depending on the cellulose source. In recent years, nanocellulose has been attracting much attention as a new bio-based nanomaterial with excellent optical properties, high strength and specific surface area. Nanocellulose can be extracted and chemically modified for a wide range of applications in the field of nanocomposites. Various agricultural crops and residues, such as soy hulls and wheat straw, sugar beet pulp, potato pulp and rutabaga, are already considered as raw materials for new cost-effective methods of nanocellulose production.

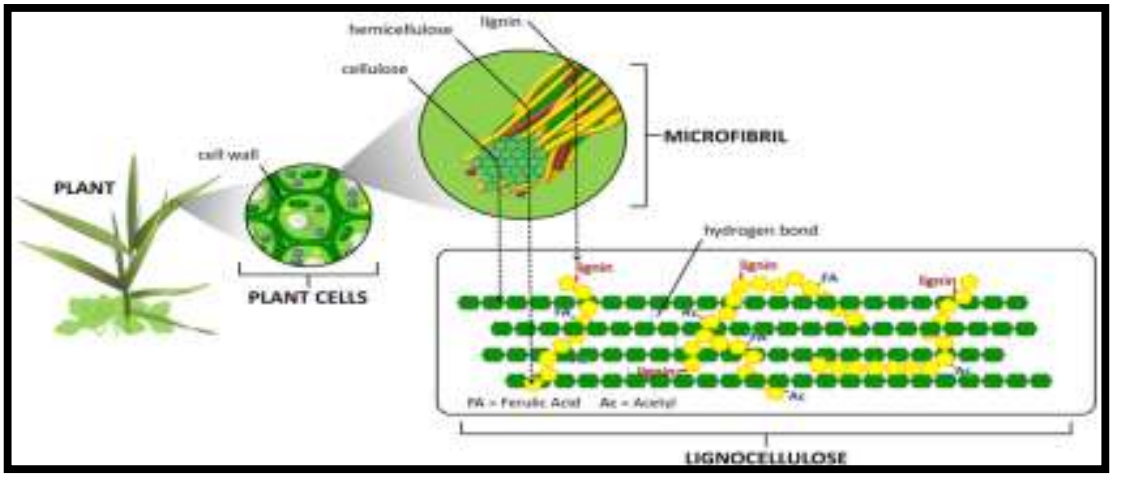

Fig-4: A simplified structure of insoluble plan fiber showing the crystalline cellulose in green and hemicellulose in yellow and its linkages with lignin, acetyl (AC), and ferulic acid (FA). 


\section{Rice husk-derived Si nanomaterials}

FAO's preliminary forecast of global paddy production in 2017 is set at 503.8 million tons (milled basis). About $25 \%$ of this production is rice husk ( $\mathrm{RH})$ which is disposed as a by-product of rice milling. The $\mathrm{RH}$ is the coating on a grain of rice which has the role to protect the seed during the crop cycle. RHs are mainly composed of lignocellulose (ca. 72-85 wt \%) and silica (ca. 15- 28 wt \%). Silicon is the second element of importance in the Earth's crust. Grasses assimilate large amounts of Si during their entire life cycle and deposit it into phytoliths as amorphous hydrated silica (SO2 $\mathrm{nH} 2 \mathrm{O}$ ). The Si content in the ash of grasses can reach 50-70\%. Silica nanoparticles (nSi) have numerous potential applications in drug delivery and biomedicine, and in agriculture, as well. According to the principles of green chemistry and among the available agricultural raw materials, $\mathrm{RH}$ is considered to be a cost-effective bioprecursor for biosynthesis of nSi (Figure 5).

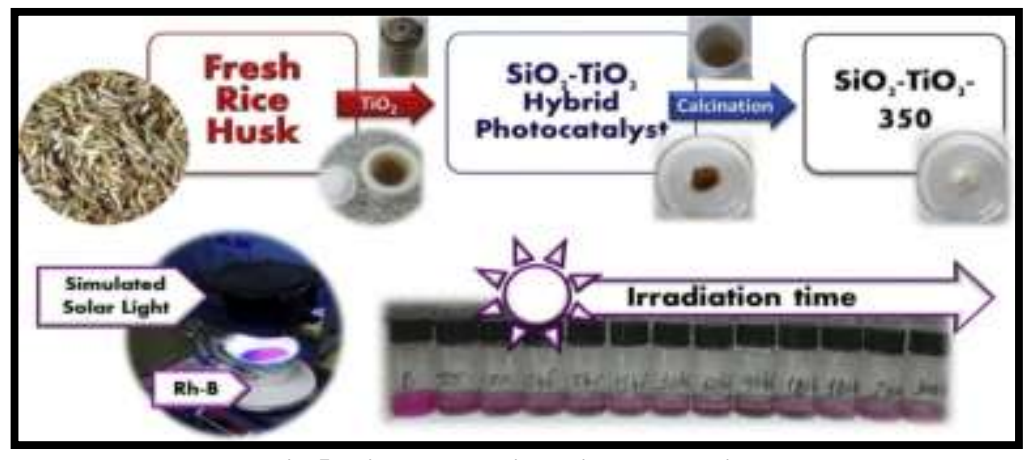

Fig-5: Rice husk-derived si nanomaterials

\section{Graphene}

Graphene is a material consisting of a monoatomic layer of carbon atoms isolated in 2004 by Novoselov and Geim (University of Manchester, UK), who in 2010 received for that work the Nobel Prize in physics. Graphene has the mechanical strength of the diamond and the flexibility of the plastic and is already used in medicine, electronics, energy, defense and many other sectors (Figure 6). The European Commission, launched in 2013, financed The Graphene Flagship, a 10 - year research initiative financed with $€ 1$ billion, which involves more than 140 academic and commercial institutions in 23 countries. Graphene is currently produced by mechanical and chemical exfoliation of graphite crystals, chemical synthesis and thermal chemical vapor deposition. Considering the large-scale production of graphene, the use of these methods poses several problems due to high process costs and the use of toxic substances. That is why, also in this case, there is considerable interest for the development of alternative, cheaper and environmental-friendly methods. Recent studies demonstrated that it is possible to use rice husk and sugarcane bagasse to produce graphene in a rapid, scalable and cost-effective manner [27].

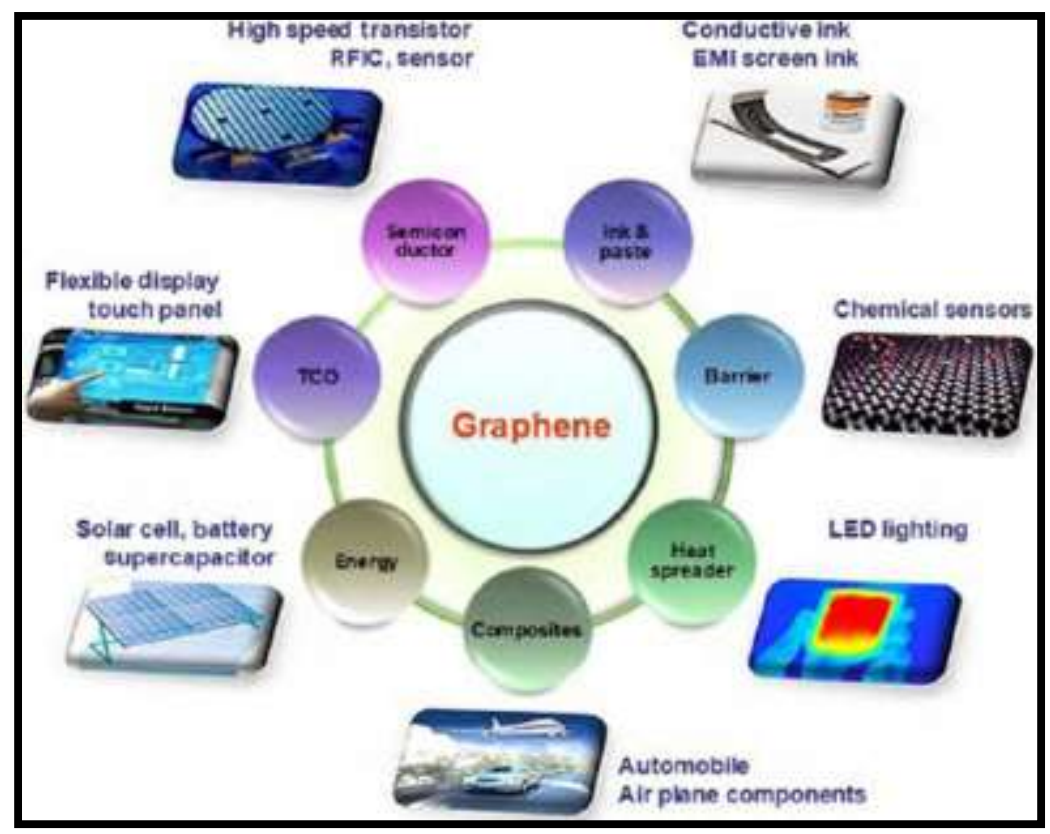

Fig-6: Graphene Applications 


\section{CONCLUSIONS}

In this review article, have inspected some as of late created thoughts concerning the potential commitments of nanotechnologies in the essential division. Right now, a few thoughts are, if not totally visionary, unequivocally anticipated into what's to come. While some different theories are extremely concrete, for some of them, the main test information is as of now accessible. Along these lines, in looking forward to the future, we can be sensibly idealistic. Be that as it may, there are various concerns connected to the handy parts of the utilization of nanomaterials in horticulture which must be tended to. By what method will nanofertilizers (or nanopesticides, nanoherbicides) be dealt with in field conditions? Which prudent criteria ought to be considered? Which hardware or machines will be utilized? Will these be a similar gear or machines utilized for mass materials? What ought to be the wellbeing condition for laborers? On these viewpoints, and numerous others, the specialists should characterize rules. Clearly, on this point, there are extraordinary desires from the ventures. Taking everything into account, the usage of nanomaterials in farming despite everything needs profound essential information about the destiny of nanomaterials in the agro-condition. Nonetheless, a progressively develop and, simultaneously, an exceptionally encouraging part of the associations among farming and nanotechnology are that as to the valorization of waste materials. In this way, it is proper to emphasize by and by that nanotechnologies are in wild advancement. This implies applications at present being worked on will before long be surpassed by different thoughts that will understand different issues in the field of supportable agribusiness. This standard is only the main impetus of the improvement of information and the fortifying of innovation applications

\section{REFERENCES}

1. Afsharinejad A, Davy A, Jennings B. Dynamic channel allocation in electromagnetic nanonetworks for high resolution monitoring of plants. Nano Communication Networks. 2016;7:2-16.

2. Alloway BJ. Heavy metals and metalloids as micronutrients for plants and animals. In: Alloway B, editor. Heavy Metals in Soils. Environmental Pollution. Vol. 2013, 22. Dordrecht: Springer; 2013. pp. 195-209.

3. Amthor J. Improving photosynthesis and yield potential. In: Ranalli P, editor. Improvement of Crop Plants for Industrial End Uses. Dordrecht: Springer; 2007. pp. 27-58.

4. Aouada FA, de Moura MR. Nanotechnology applied in agriculture: Controlled release of agrochemicals. In: Rai M, Ribeiro C, Mattoso L, Duran N, editors. Nanotechnologies in Food and Agriculture. Springer, Cham. 2015: 103-118.

5. Ashworth GS, Azevedo P, editors. Agricultural Wastes. Nova Science Publishers, Inc. 2009: 306.
6. Baligar VC, Fageria NK. Nutrient use efficiency in plants: An overview. In: Rakshit A, Singh HB, Sen A, editors. Nutrient Use Efficiency: From Basics to Advances. New Delhi: Springer. 2015: 1-14.

7. Bouwman L, Goldewijk KK, Van Der Hoek KW, Beusen AHW, Van Vuuren DP, Willems J, Rufino MC, Stehfesta E. Exploring global changes in nitrogen and phosphorus cycles in agriculture induced by livestock production over the 1900 2050 period. Proceedings National Academy of Science USA. 2013;110(52):20882-20887.

8. Chandra R, Takeuchi H, Hasegawa T. Methane production from lignocellulosic agricultural crop wastes: a review in context to second generation of biofuel production. Renew and Sustain Energy Rev. 2012;16(3):1462-1476.

9. Chhipa H. Nanofertilizers and nanopesticides for agriculture. Environmental Chemistry Letters. 2016;15(1):15-22.

10. Corradini E, de Moura MR, Mattoso LHC. A preliminary study of the incorparation of NPK fertilizer into chitosan nanoparticles. eXPRESS Polymer Letters. 2010;4(8):509-515.

11. Dimkpa CO, Bindraban PS. Nanofertilizers: new products for the industry?. Journal of agricultural and food chemistry. 2017 May 24;66(26):6462-73.

12. Ditta A, Arshad M. Applications and perspectives of using nanomaterials for sustainable plant nutrition. Nanotechnology Reviews. 2016;5(2):1-22.

13. Eriksen A, Kjeldby M. A comparative study of urea hydrolysis rate and ammonia volatilization from urea and urea calcium nitrate. Fertilizer Research. 1987;11(1):9-24.

14. Evans JR. Improving photosynthesis. Plant Physiology. 2013;162:1780-1793.

15. Ezz El-Din H, Manjaiah DH. Internet of nano things and industrial internet of things. In: Acharjya D, Geetha $M$, editors. Internet of Things: Novel Advances and Envisioned Applications. Studies in Big Data. Cham: Springer; 2017. pp. 109-123.

16. FAO. World agriculture towards 2030/2050: the 2012 revision [Internet]. 11/06/212. Available from: http://www.fao.org/docrep/016/ap106e/ap106e.pdf [Accessed: October 24, 2017].

17. Food wastage Footprint-Impacts on natural resources: summary report. Food and Agriculture Organization of the United Nations, Europe: Springer; 2003.

18. Fraceto LF, Grillo $\mathrm{R}$, de Medeiros GA, Scognamiglio V, Rea G, Bartolucci C. Nanotechnology in agriculture: Which innovation potential does it have? Frontiers in Environmental Science. 2016;4:20.

19. Gao FQ, Hong FS, Liu C, Zheng L, Su MY. Mechanism of nano-anatase $\mathrm{TiO} 2$ on promoting photosynthetic carbon reaction of spinach: Inducing 
complex of Rubisco-Rubisco activase. Biology Trace Elements Research. 2006;111(1-3):239-253.

20. Gao FQ, Liu C, Qu CX, Zheng L, Yang F, Su MG, Hong FH. Was improvement of spinach growth by nano-TiO2 treatment related to the changes of rubisco activase? Biometals. 2008;21:211-217.

21. Giraldo JP, Landry MP, Faltermeier SM, McNicholas TP, Iverson MN, Boghossian AA, Reuel NF, Hilmer AJ, Sen F, Brew J, Strano MS. Plant nanobionics approach to augment photosynthesis and biochemical sensing. Nature Materials. 2014; 13:400-408.

22. Hibberd JM, Sheehy JE, Langdale JA. Using C4 photosynthesis to increase the yield of rice rationale and feasibility. Current Opinion in Plant Biology. 2008; 112:228-231.

23. Hong F, Zhou J, Liu C, Yang F, Wu C, Zheng L, Yang P. Effect of nano-TiO2 on photochemical reaction of chloroplasts of spinach. Biology Trace Elements Research. 2005a;105 (1-3):269-279.

24. Hong FS, Yang F, Ma ZN, Zhou J, Liu C, Wu C, Yang P. Influences of nano-TiO2 on the chloroplast ageing of spinach under light. Biology Trace Elements Research. 2005b;1043: 249-260.

25. Lei Z, Mingyu S, Chao L, Liang C, Hao H, Xiao W, Xiaoqing L, Fan Y, Fengqing G, Fashui H. Effects of nanoanatase $\mathrm{TiO} 2$ on photosynthesis of spinach chloroplasts under different light illumination. Biology Trace Elements Research. 2007;1191:68-76.

26. Long SP, Zhu X-G, Naidu SL, Ort DR. Can improvement in photosynthesis increase crop yields? Plant Cell Environment. 2006;29:315-330.

27. Luca Marchiol, Nanotechnology in Agriculture: New Opportunities and Perspectives, http://dx.doi.org/10.5772/intechopen.74425.

28. Ma L, Liu C, Qu C, Yin S, Liu J, Gao F, Hong F. Rubisco activase mRNA expression in spinach: Modulation by nanoanatase treatment. Biology Trace Elements Research. 2008; 1222:168-178.

29. Manjunatha SB, Biradar DP, Aladakatti YR. Nanotechnology and its applications in agriculture: A review. Journal Farm Science. 2016;29:1-13.

30. Marshner H. Mineral Nutrition of Higher Plants. 3rd ed. London: Elsevier/Academic Press. 2012:672.

31. McGrath JM, Long SP. Can the cyanobacterial carbon-concentrating mechanism increase photosynthesis in crop species? A theoretical analysis. New Phytologist. 1644;2014:2247- 2261.

32. Melis A. Solar energy conversion efficiencies in photosynthesis: Minimizing the chlorophyll antennae to maximize efficiency. Plant Science. 1774;2009:272-280.

33. Millan G, Agosto F, Vazquez M. Use of clinoptilolite as a carrier for nitrogen fertilizers in soils of the Pampean regions of Argentina. Ciencia Investigación Agraria. 2008;35:293-302.
34. Monreal CM, DeRosa M, Mallubhotla SC, Bindraban PS, Dimkpa C. Nanotechnologies for increasing the crop use efficiency of fertilizer-micronutrients. Biology Fertility Soils. 2016; 52:423-437.

35. Morales-Díaz AB, Ortega-Ortíz H, Juárez-Maldonado A, Cadenas-Pliego G, GonzálezMorales S, Adalberto Benavides-Mendoza A. Application of nanoelements in plant nutrition and its impact in ecosystems. Advances in Natural Sciences: Nanoscience and Nanotechnology. 2017;8:1-13.

36. Mortved JJ. Micronutrient fertilizers and fertilization practices. Nutrient Cycling in Agroecosystems. 1985;7:1,221-1,235.

37. Mousavi SR, Rezaei M. Nanotechnology in agriculture and food production. Journal of Applied Environmental and Biological Sciences. 2011;1:10,414-10,419.

38. Mufamadi MS, Sekhejane PR. Nanomaterial-based biosensors in agriculture application and accessibility in rural smallholding farms: Food security. In: Prasad R, Kumar M, Kumar V, editors. Nanotechnology. Singapore: Springer; 2017. pp. 263-278.

39. Nayyar A, Puri V, Le D-N. Internet of nano things (IoNT): Next evolutionary step in nanotechnology. Nanoscience and Nanotechnology. 2017;7(1):4-8.

40. Noji T, Kamidaki C, Kawakami K, Shen JR, Kajino T, Fukushima Y, Sekitoh T, Itoh S. Photosynthetic oxygen evolution in mesoporous silica material: Adsorption of photosystem II reaction center complex into $23 \mathrm{~nm}$ nanopores in SBA. Langmuir. 2011;272:705-713.

41. OECD. Glossary of Statistical Terms. Paris; 2009.

42. Page V, Feller U. Heavy metals in crop plants: Transport and redistribution processes on the whole plant level. Agronomy. 2015;5:447-463.

43. Parisi C, Vigani M, Rodríguez-Cerezo E. Proceedings of a Workshop on Nanotechnology for the Agricultural Sector: From Research to the Field. EUR - Scientific and Technical Research Series. 2014. 40.

44. Perrin TS, Drost DT, Boettinger JL, Norton JM. Ammonium-loaded clinoptilolite: A slowrelease nitrogen fertilizer for sweet corn. Journal Plant Nutrition. 1998;21:515-530.

45. Prasad R, Bhattacharyya A, Nguyen QD. Nanotechnology in sustainable agriculture: Recent developments, challenges, and perspectives. Frontiers in Microbiology. 2017;8: 1014.

46. Qi M, Liu Y, Li T. Nano-TiO2 improve the photosynthesis of tomato leaves under mild heat stress. Biology Trace Elements Research. 2013;156(1-3):323-328.

47. Ramos Campos EV, de Oliveira JL, Fernandes Fraceto L, Singh B: Polysaccharides as safer release systems for agrochemicals. Agronomy for Sustainable Development. 2015; 35:47- 66. 
48. Robert PC, Rust RH, WEA L, editors. Site-Specific Management for Agricultural Systems. Madison, WI: ASA-CSSA-SSSA; 1995. 933.

49. Servin A, Elmer W, Mukherjee A, De la Torre-Roche R, Hamdi H, White JC, Bindraban P, Dimkpa C. A review of the use of engineered nanomaterials to suppress plant disease and enhance crop yield. Journal of Nanoparticle Research. 2015;17:92.

50. Singh Nee Nigam P, Pandey A. Biotechnology for agro-industrial residues Utilisation. In: Poonam Singh Nigam et al. editors. Netherlands: Springer; 2009. 466.

51. Singha MR, Bell AT. Design of an artificial photosynthetic system for production of alcohols in high concentration from CO2. Energy \& Environmental Science. 2016;9:193- 199.

52. Spreitzer RJ, Salvucci ME. Rubisco: Structure, regulatory interactions, and possibilities for a better enzyme. Annual Reviews in Plant Biology. 2002;53:449-475.

53. Stewart WM, Dibb DW, Johnston AE, Smyth TJ. The contribution of commercial fertilizer nutrients to food production. Agronomy Journal. 2005;7(1):1-6.

54. Sutton MA, Bleeker A, Howard CM, Erisman JW, Abrol YP, Bekunda M, Datta A, Davidson E, de Vries W, Oenema O, Zhang FS. Our nutrient world. The challenge to produce more food \& energy with less pollution. Key messages for Rio+20. Published by the Centre for Ecology \& Hydrology on Behalf of the Global Partnership on Nutrient Management (GPNM) and the International Nitrogen Initiative (INI), 2012.
55. Tan DKY, Amthor JS. Bioenergy. In: Dubinsky Z, editor. Photosynthesis. Intech; 2013: 299-330.

56. Tepe O, Dursun AY. Exo-pectinase production by Bacillus pumilus using different agricultural wastes and optimizing of medium components using response surface methodology. Environ Sci Pollut Res In. 2014;21(16):9911-9920.

57. US House of Representatives; 1997: Section 2.1.A Precision Agriculture. Online source:http://www.gpo.gov/fdsys/pkg/BILLS-105h r725ih/html/BILLS-105hr725ih.htm.

58. Wang Q, Zhang QD, Zhu XG, Lu CM, Kuang TY, Li CQ. PSII photochemistry and xanthophyll cycle in two superhigh-yield rice hybrids, Liangyoupeijiu and Hua-an 3 during photoinhibition and subsequent restoration. Acta Botanica Sinica. 2002;4411:1297- 1303.

59. Welch RM, Shuman L. Micronutrient nutrition of plants. Critical Reviews in Plant Sciences. 1995;14(1):49-82.

60. Wu A, Song Y, van Oosterom EJ, Hammer GL. Connecting biochemical photosynthesis models with crop models to support crop improvement. Frontiers in Plant Science. 2016;7: 1518.

61. Zhu X-G, Long SP, Ort DR. Improving photosynthetic efficiency for greater yield. Annual Reviews in Plant Biology. 2010; 61:235-261.

62. Zuverza-Mena N, Martínez-Fernández D, Du W, Hernandez-Viezcas JA, Bonilla-Bird N, López-Moreno ML, Komárek M, Peralta-Videa JR, Gardea-Torresdey JL. Exposure of engineered nanomaterials to plants: Insights into the physiological and biochemical responses-a review. Plant Physiology Biochemistry. 2017; 110:236-264. 